\title{
O PRINCÍPIO DO CONTRADITÓRIO NO NOVO CÓDIGO DE PROCESSO CIVIL E A QUESTÃO DAS DECISÕES SURPRESAS
}

THE CONTRADITORY PRINCIPLE IN THE NEW CIVIL PROCEDURE CODE AND THE

QUESTION OF SURPRISED DECISIONS

Leonardo Barbosa CARVALHO ${ }^{1}$

Daiene Kelly GARCIA ${ }^{2}$

ISSUE DOI: $10.21207 / 2675-0104.2018 .769$

\begin{abstract}
RESUMO
O presente artigo tem por objetivo analisar o princípio do contraditório e a vedação das decisões surpresas. Com a vigência do Novo Código de Processo Civil, o referido princípio ganhou nova perspectiva no cenário nacional, a chamada dimensão substancial, sendo que uma de suas principais funções é garantir que não haja imprevisto no curso do processo. Portanto, de acordo com a nova sistemática adotada pela legislação processual civil, a consequência da não observação da garantia de não-surpresa é a nulidade da decisão que a violar. Precipuamente, o trabalho aborda uma breve noção das ideias de princípio e de contraditório. Em seguida, analisa-se a nova dimensão do princípio do contraditório, denominada de substancial. Passa-se, então, à análise das normas fundamentais do Novo Código de Processo Civil e a adoção da concepção substancial. Analisa-se, por fim, a garantia de não-surpresa e as consequências de seu descumprimento, verificando a jurisprudência do Colendo Superior Tribunal de Justiça sobre o tema.
\end{abstract}

Palavras-chave: Direito processual civil. Princípio do contraditório. Decisão-surpresa.

\footnotetext{
${ }^{1}$ Discente da Faculdade de Direito de Franca (FDF), Franca/SP. Bolsista do Programa Interno de Iniciação Científica (PIBIC 2017-2018).

${ }^{2}$ Mestre em Direito pelo Programa de Pós-Graduação da Universidade Estadual Paulista "Júlio de Mesquita Filho" - Faculdade de Ciências Humanas e Sociais (2014). Graduada em Direito pela Faculdade de Direito de Franca (2009). Advogada inscrita na OAB em SP e MG. Possui experiência docente em cursos de Direito, produção científica e trabalhos técnicos.
} 


\section{ABSTRACT}

The purpose of this article is to analyze the principle of contradictory and the fence of surprise decision. With the validity of the New Code of Civil Procedure, this principle gained new perspective in the national scenario, the so-called substantial dimension, one of its main functions being to ensure that there is no unforeseen in the course of the process. Therefore, according to the new system adopted by the civil procedural law, the consequence of not observing the guarantee of nonsurprise is the nullity of the decision that violates it. On the face of it, the paper deals with a brief notion of the ideas of principle and contradictory. Next, we analyze the new dimension of the contradictory principle, called substantial. We then proceed to the analysis of the fundamental norms of the New Code of Civil Procedure and the adoption of the substantial concept. Finally, the assurance of non-surprise and the consequences of its noncompliance are analyzed, verifying the jurisprudence of the Superior Court of Justice on the subject.

Keywords: Civil procedural law. Principle of contradictory. Surprise decision

\section{INTRODUÇÃO}

O acesso à justiça, no ordenamento jurídico brasileiro, constitui direito fundamental, sendo essencial para a realização da justiça. Está previsto no artigo $5^{\circ}$, inciso XXXV, da Constituição Federal, o qual dispõe que "a lei não excluirá da apreciação do Poder Judiciário lesão ou ameaça a direito"3. Dessa forma, qualquer a lesão ou ameaça a direito poderá ser levada ao conhecimento do Poder Judiciário, que terá o poder e o dever de dar a solução ao caso concreto.

Ocorre que, para alcançar a justa resolução dessas lides, o exercício da jurisdição deve obedecer a diversos princípios fundamentais, dentre os quais se destaca o princípio do contraditório, o qual garante às partes a plena defesa de seus interesses e concede ao magistrado os elementos necessários para a solução dos conflitos de interesses.

Com a elaboração do Código de Processo Civil de 2015, o princípio do contraditório obteve uma nova perspectiva, mais dinâmica, substancial e efetiva, na qual as partes possuem mais influência no decidir do magistrado.

Em decorrência desta garantia processual, é vedado ao juiz proferir decisões surpresas, ou seja, decidir com base em fundamento a respeito do qual não se tenha dado às partes a oportunidade de manifestarem previamente, qualquer que seja o juízo ou grau de jurisdição, ainda que se trate de matéria que deva decidir de ofício.

\footnotetext{
${ }^{3}$ BRASIL. Constituição (1988). Constituição da República Federativa do Brasil. Disponível em: <http://www.planalto.gov.br/ccivil_03/constituicao/constituicaocompilado.htm〉. Acesso em: 10 ago. 2018.
} 
O presente artigo, desse modo, visa analisar as novas perspectivas conferidas ao princípio do contraditório a partir da vigência do Novo Código de Processo Civil, bem como a proibição das decisões surpresas e as consequências práticas da inobservância do instituto.

\section{UM BREVE HISTÓRICO DO CONTRADITÓRIO NO PROCESSO CIVIL}

O Poder Constituinte sempre deixou de lado o princípio do contraditório no processo no que se refere ao processo civil. Não é por outro motivo que as Constituições anteriores à de 1988 deixaram de consagrar, de maneira expressa, o contraditório como garantia processual desta área. A verdade é que as Cartas Magnas pretéritas sempre se referiram à ampla defesa e ao contraditório direcionadas somente ao processo penal.

No entanto, a doutrina, apesar da omissão constitucional existente, nunca deixou de empreender estudos para fazer com que o processo civil também fosse atingido pelos princípios do contraditório e da ampla defesa, ainda que não consagrados expressamente naquelas Constituições ${ }^{4}$.

Em razão da ideia de contraditório sempre ter sido relacionada à instrução criminal, muitos constitucionalistas concluíam que o princípio somente se aplicava ao processo penal. Porém, esse entendimento foi superado ao longo do tempo, em virtude de interpretações mais completas da Constituição.

Atualmente, a garantia do contraditório está inserida no artigo 5. ${ }^{\circ}$, inciso LV, da Constituição Federal de 1988, o qual dispõe que "aos litigantes, em processo judicial e administrativo, e aos acusados em geral são assegurados o contraditório e a ampla defesa, com os meios e recursos a ela inerentes" ${ }^{\prime \prime}$.

Ao analisar a atual redação constitucional, é possível notar a mudança de paradigma no que tange à garantia do contraditório, uma vez que a atual Carta Magna incluiu expressamente o processo civil e o

\footnotetext{
${ }^{4}$ MESQUITA, Gil Ferreira de. Princípios do contraditório e da ampla defesa no processo civil brasileiro. São Paulo: Editora Juarez de Oliveira, 2003. p. 123.

${ }^{5}$ BRASIL. Constituição (1988). Constituição da República Federativa do Brasil. Disponível em: <http://www.planalto.gov.br/ccivil_03/constituicao/constituicaocompilado.htm〉. Acesso em: 12 mar. 2018.
} 
processo administrativo na esfera de aplicação desta garantia, sendo que ela proporcionou efeitos em toda a legislação infraconstitucional, inclusive em relação ao Novo Código de Processo Civil.

O contraditório era entendido como um mero princípio externo e formal, o qual não proporcionava os resultados esperados aos processos, deixando de legitimar de maneira devida o órgão judiciário que resolvia os conflitos de interesses.

Todavia, após a segunda metade do século $\mathrm{XX}$, as reinvindicações por uma nova ordem social e processual trouxeram em suas pautas novos valores, como, por exemplo, a efetividade do processo, os quais começaram a ser previstos inclusive nos textos constitucionais ${ }^{6}$.

Além disso, o surgimento de novos fenômenos modernos fez com que a garantia do contraditório fosse repensada de uma maneira descomplicada. Assim, até meados da década de 1950, era natural a interpretação e a aplicação de determinado ramo do direito com base somente nas principais leis ordinárias que o regulamentava.

Porém, atualmente, a influência dos direitos fundamentais sobre o direito processual tem ajudado, de maneira significativa, para a constante e profunda mudança de seus elementos teóricos e operativos.

A garantia do contraditório, assim, assume uma nova posição, trazendo à tona a necessidade do diálogo entre as partes e o juiz para a formação da decisão final. Incentiva-se, assim, a construção conjunta da decisão judicial. Atualmente, a prioridade é que se tenha uma decisão judicial o mais perto possível da realidade debatida, dando-se preferência ao mérito ao invés do formalismo.

Essa moderna ideia de contraditório ganha espaço no Brasil com a promulgação da Constituição Federal de 1988, a qual previu expressamente o contraditório como um princípio constitucional a ser adotado em todas as esferas processuais. Além disso, a partir do Código de Processo Civil de 2015, fica ainda mais nítida adesão ao contraditório substancial, conforme se analisará adiante.

Com a nova noção do princípio do contraditório, pode-se dizer que os anseios de influência das partes no processo e não-surpresa nas decisões judiciais devem ser observados em respeito à nova lei, sob pena de invalidação da decisão judicial, demostrando a importância desta garantia para o processo civil.

\footnotetext{
${ }^{6}$ RUBIN, Fernando. O contraditório na visão cooperativa do processo. Revista Dialética de Direito Processual - RDDP. São Paulo, SP. n. 94. jan./2011. p. 29.
} 


\section{3}

\section{UMA NOVA DIMENSÃO DO PRINCÍPIO DO CONTRADITÓRIO}

Segundo Nelson Nery Junior, "por contraditório deve entenderse, de um lado, a necessidade de dar conhecimento da existência da ação e de todos os atos do processo às partes, e, de outro, a possibilidade de as partes reagirem aos atos que lhe sejam desfavoráveis"7.

O princípio do contraditório é a consequência do princípio democrático da estrutura processual. A democracia pode ser entendida como participação, a qual, no processo, revela-se pela efetivação da garantia do contraditório. O princípio do contraditório deve ser enxergado, portanto, como a exigência para o exercício democrático de um poder ${ }^{8}$.

Tradicionalmente, são apontadas duas dimensões do princípio do contraditório: a dimensão meramente formal e a dimensão substancial.

Permitir a participação da parte no processo é a dimensão formal do princípio do contraditório. Trata-se do direito de ser comunicado dos atos processuais e, assim, poder se manifestar, podendo ser entendida, em outras palavras, como a garantia de falar.

Essa é a proteção mínima do princípio do contraditório e traduz a visão clássica que se tem sobre o tema. De acordo com essa perspectiva, o magistrado efetiva a garantia do contraditório pelo simples fato de dar vista dos autos à parte, permitindo que ela se manifeste sobre determinado assunto abordado pela parte contrária.

Algumas obras clássicas da literatura jurídica propagaram a ideia de contraditório como o princípio da audiência bilateral, com base na perspectiva de que ao réu deve ser garantida a oportunidade de se defender ${ }^{9}$. Esse entendimento estático, inerte, do contraditório continua, infelizmente, ainda sendo transmitida e assimilada por profissionais do direito.

A função do contraditório, portanto, sob a ótica formal, é permitir a oportunidade de a parte reagir ou evitar posição jurídica

\footnotetext{
${ }^{7}$ NERY JUNIOR, Nelson. Princípios do processo civil na constituição federal. 8. ed. São Paulo: Revista dos Tribunais, 2004. p. 172.

${ }^{8}$ MARINONI, Luiz Guilherme. Novas linhas do processo civil. 4. ed. São Paulo: Malheiros, 2000. p. 255-258.

9 CINTRA, Antônio Carlos de Araújo; GRINOVER, Ada Pellegrini; DINAMARCO, Cândido Rangel. Teoria geral do processo. 24. ed. São Paulo: Malheiros, 2008. p. 61.
} 
desfavorável. Verifica-se, assim, um binômio fundamental ao redor do qual gravita o princípio: informação-reação ${ }^{10}$.

Todavia, atualmente, o contraditório não pode ser entendido como mera informação-reação. Existe, pois, um verdadeiro substrato democrático a ser permitido e garantido dentro do processo, o que modernamente é chamado de contraditório substancial ou material.

De acordo com José Manuel Lebre de Freitas, a noção de contraditório como audiência bilateral é oportuno, todavia, é muito restrito. Para o autor, é preciso que esse conceito seja complementado por uma ideia mais extensiva de contraditoriedade, que pode ser expressa como a garantia de participação ativa das partes no decorrer do processo $^{11}$.

Nas palavras do referido autor, essa garantia consubstancia-se da seguinte forma:

\begin{abstract}
Mediante a possibilidade de, em plena igualdade, influírem em todos os elementos (factos, provas, questões de direito) que se encontrem em ligação com o objecto da causa e que em qualquer fase do processo apareçam como potencialmente relevantes para a decisão. O escopo principal do princípio do contraditório deixou assim de ser a defesa, no sentido negativo de oposição ou resistência à actuação alheia, para passar a ser a influência, no sentido de direito de incidir activamente no desenvolvimento e no êxito do processo ${ }^{12}$.
\end{abstract}

Não basta viabilizar que a parte participe do litígio, pois somente isto não é o bastante para que se consagre o princípio do contraditório. Para a sua efetivação, é preciso que se autorize que a parte seja ouvida, no processo, em condições de influenciar a decisão a ser proferida pelo magistrado.

Os acontecimentos do século XX, principalmente as Guerras Mundiais e a queda dos regimes ditatoriais, trouxeram ao processo uma valoração em sentido democrático, que tinha sido deixado de lado. É nesse diapasão que o princípio do contraditório substancial se mostra totalmente relevante aos procedimentos civis, uma vez que consagra direitos fundamentais dentro do processo.

\footnotetext{
${ }^{10}$ CABRAL, Antônio do Passo. O contraditório como dever e a boa-fé processual objetiva. Revista de Processo. São Paulo, SP. v. 126. ago./2005. p. 61.

${ }^{11}$ FREITAS, José Lebre de. Introdução ao processo civil: conceito e princípios gerais à luz do código revisto. Coimbra: Coimbra Editora, 1996. p. 96-97.

${ }^{12}$ FREITAS, José Lebre de. Introdução ao processo civil: conceito e princípios gerais à luz do código revisto. Coimbra: Coimbra Editora, 1996. p. 96-97.
} 
Portanto, o princípio do contraditório deve sofrer uma transformação em seu significado, deixando de ser entendido como meramente formal e passando a ser encarado como substancial, com o escopo de criar uma nova maneira de encarar o processo.

Sobre o tema, escreve Eduardo Lamy:

\begin{abstract}
Desse modo, atualmente, o processo não é mais apenas um meio formal preocupado com o seu respeito acima do próprio direito material, através do qual apenas a jurisdição diz o direito, limitando-se a responder aos pleitos que lhe são formulados. Hoje, o direito processual dever ser conceituado como resultado da operação de um núcleo de direitos fundamentais, especialmente a ampla defesa e o devido processo legal, que atuam sobre uma base procedimental formada de meios que necessitam adequar-se aos fins de forma tão rica quanto a diversidade dos direitos materiais a serem tutelados ${ }^{13}$.
\end{abstract}

Apenas no momento em que os juristas perceberem a dimensão e a importância do princípio do contraditório como base do processo civil, que não está fundamentado somente na técnica da audiência bilateral, é que estarão prontos para avaliar a combater os diversos casos em que são proferidas decisões surpresas.

\title{
4 O PRINCÍPIO DO CONTRADITÓRIO E O NOVO CÓDIGO DE PROCESSO CIVIL BRASILEIRO
}

O Código de Processo Civil de 2015, em seu Capítulo I, traz as normas fundamentais que devem ser observadas no trâmite de todos os procedimentos. Trata-se de um capítulo que tem por objetivo guiar todo o sistema procedimental, dando destaque aos princípios, adequando-se às normas constitucionais, que concedem garantias fundamentais aos litigantes, e fazendo com que a conceituação de processo alcance uma qualificação justiça $\mathrm{a}^{14}$.

\footnotetext{
13 LAMY, Eduardo de Avelar. Considerações sobre a influência dos valores e direitos fundamentais no âmbito da teoria processual. Disponível em: <https://periodicos.ufsc.br/index.php/sequencia/article/view/2177-7055.2014v35n69p301〉. Acesso em: 18 mar. 2018.

${ }^{14}$ THEODORO JÚNIOR, Humberto. A Constitucionalização do processo no estado democrático brasileiro. In: CÂMARA, Alexandre Freitas; GAIO JÚNIOR, Antônio Pereira (Coord.). Novo CPC: reflexões e perspectivas. Belo Horizonte: Del Rey, 2014. p. 184.
} 
O referido diploma, portanto, preocupa-se com os princípios constitucionais, garantindo o efetivo contraditório e a cooperação entre as partes e o magistrado, materializando a democratização do processo judicial $^{15}$.

Todavia, a simples adoção dos princípios do contraditório e da ampla defesa tal como era não seria suficiente para provocar mudança no enfoque de como esses princípios eram vistos e adotados pelos juristas e doutrinadores desde o diploma de 1973. Assim, o Poder Legislativo sentiu a necessidade de confeccionar uma nova norma processual capaz de proporcionar uma releitura ao princípio do contraditório no processo civil brasileiro.

A mencionada norma foi estabelecida no artigo 10 do Novo Código de Processo Civil, o qual vale a pena transcrever: "Art. 10. O juiz não pode decidir, em grau algum de jurisdição, com base em fundamento a respeito do qual não se tenha dado às partes oportunidade de se manifestar, ainda que se trate de matéria sobre a qual deva decidir de ofício" $"$.

Pela leitura do referido dispositivo, é possível perceber que o legislador garantiu, de maneira expressa, o direito de os demandantes influenciarem e discutirem os fundamentos que serão utilizados para a construção da decisão judicial.

Dessa forma, a fim de modificar o desenvolvimento do processo, o novo diploma processual proíbe a faculdade de o juiz decidir, em qualquer grau de jurisdição, com escopo em fundamento em que os litigantes não puderam se manifestar. $\mathrm{O}$ dispositivo determina, ainda, que essa vedação também se aplica às hipóteses em que a matéria possa ser conhecida de ofício pelo magistrado, ou seja, quando se tratar de matéria de ordem pública, que não se submete à preclusão.

O sistema aderido pelo Código de Processo Civil de 1973 não valorizava a cooperação entre as partes e o magistrado na resolução da lide. Ao contrário, o referido diploma adotou o modelo contencioso estrategista, uma espécie de duelo entre as partes, inexistindo

\footnotetext{
15 THEODORO JÚNIOR, Humberto. A Constitucionalização do processo no estado democrático brasileiro. In: CÂMARA, Alexandre Freitas; GAIO JÚNIOR, Antônio Pereira (Coord.). Novo CPC: reflexões e perspectivas. Belo Horizonte: Del Rey, 2014. p. 184.

16 BRASIL. Lei 13.105/2015 (Novo Código de Processo Civil). Disponível em: <http://www.planalto.gov.br/CCIVil_03/_Ato2015-2018/2015/Lei/L13105.htm〉. Acesso em: 10 maio 2018.
} 
comunicação entre os litigantes, o que se mostra em desacordo com as normas constitucionais que garantem o contraditório e a isonomia ${ }^{17}$.

Diferentemente, o novo modelo de contraditório adotado pelo Código de Processo Civil de 2015 surge para modificar o caráter estritamente contencioso das demandas e a impor aos processos o princípio da cooperação entre os litigantes, seus patronos e o juiz.

Sobre o princípio da cooperação, escreve Fernanda Tartuce:

O princípio da cooperação aplicado ao processo enseja que durante a tramitação do feito os magistrados, as partes e seus mandatários colaborem entre si e concorram para a obtenção breve e eficaz da justa composição da controvérsia; essa importante diretriz objetiva transformar o processo civil em uma "comunidade de trabalho" e responsabilizar tanto as partes quanto o tribunal pelos resultados ao final alcançados ${ }^{18}$.

Portanto, o princípio da cooperação possui grande influência no trabalho do magistrado, que fica obrigado a não surpreender os litigantes no curso do processo, dando-lhes não somente a chance de se manifestarem em relação aos atos processuais, mas também de deixar claro, antes de proferir qualquer decisão, os fundamentos que serão utilizados para a conclusão do julgamento.

Vale destacar, ainda, que o Novo Código de Processo Civil, ao adotar a concepção substancial do princípio do contraditório, também causou uma mudança na aplicação do princípio da motivação das decisões judiciais.

O princípio da motivação das decisões judiciais pressupõe a obrigação do juiz de prolatar uma sentença bem elaborada e apropriada ao caso sob análise, possibilitando que tanto as partes como a sociedade em geral compreendam a fundamentação utilizada. Essa necessidade de fundamentar a decisão proferida funciona como forma de sua legitimação, pois os atos praticados pelo magistrado causam reflexo em toda a jurisdição de sua atuação ${ }^{19}$.

No direito processual civil moderno e democrático, a aplicação do princípio do contraditório e da motivação das decisões judicias se dá

\footnotetext{
${ }^{17}$ TARTUCE, Fernanda. Igualdade e vulnerabilidade no processo civil. Rio de Janeiro: Forense, 2012. p. 146.

${ }^{18}$ TARTUCE, Fernanda. Igualdade e vulnerabilidade no processo civil. Rio de Janeiro: Forense, 2012. p. 146.

${ }^{19}$ OLIVEIRA NETO, Olavo de; MEDEIROS NETO, Elias Marques de; OLIVEIRA, Patrícia Elias Cozzolino de. Curso de direito processual civil. São Paulo: Verbatim, 2015. p. 150.
} 
de maneira concomitante, devendo o magistrado conceder aos litigantes o direito de influência, além de rebater, de modo fundamentado, todos os pontos trazidos pelas partes à lide. Com isso, é dado aos litigantes o poder de fiscalizar o trabalho realizado pelo magistrado, consubstanciando-se, assim, a aplicação prática do direito de influência.

\title{
5 O PRINCÍPIO DO CONTRADITÓRIO E A QUESTÃO DAS DECISÕES SURPRESAS
}

A não-surpresa pode ser entendida como o direito das partes ao prévio debate sobre todas as questões que foram relevantes para o deslinde do processo, concedendo-lhes a chance de manifestar, arguir elementos probatórios e impugnar o alegado pela outra parte ou suscitado pelo juiz, uma vez que é vedado magistrado motivas suas decisões com base em argumentos não invocados pelos litigantes.

Sobre a garantia de não surpresa, aduz Dierle Nunes:

\begin{abstract}
Impõe ao juiz o dever de provocar o debate acerca de todas as questões, inclusive as de conhecimento oficioso, impedindo que em "solitária onipotência" aplique normas ou embase a decisão sobre fatos completamente estranhos à dialética defensiva de uma ou de ambas as partes ${ }^{20}$.
\end{abstract}

A decisão surpresa, desse modo, trata-se de uma forma ilegal de pronunciamento judicial, justificada com base em fundamento obtido de maneira unilateral pelo magistrado, sem que se tenha dado a oportunidade de prévio debate entre os litigantes. O juiz profere decisão inesperada para uma ou para ambas as partes, utilizando argumentos não debatidos no curso do processo, em flagrante desrespeito ao princípio do contraditório.

A ilicitude da decisão surpresa decorre da inviabilidade dos litigantes de manifestarem acerca de todos os argumentos suscitados no processo e, assim, exercerem a influência na decisão judicial, uma vez que o magistrado fundamenta a sua decisão com base em argumentos não debatidos pelas partes no curso da demanda.

A concepção substancial do contraditório, adotada pelo Novo Código de Processo Civil, impossibilita a prolação de decisão surpresa,

${ }^{20}$ NUNES. Dierle José Coelho. Et al. Curso de direito processual civil: fundamentação e aplicação. Belo Horizonte: Fórum, 2011. p. 83. 
uma vez que o magistrado fica obrigado a submeter todas as matérias invocadas pelas partes ao crivo do contraditório antes de decidir. Trata-se, pois, da proibição da decisão surpresa, contra decisão que afronta o modelo de processo cooperativo instituído pela atual legislação processual civil, trazendo ao processo questão suscitada pelo magistrado que não foi debatida pelas partes no curso da lide.

José Miguel Garcia Medina aponta que às partes deve ser reconhecido o direito de participar ativamente no procedimento de tomada de decisão, sendo que esta participação consiste em influenciar decisivamente nos destinos do processo $^{21}$.

O Código de Processo Civil de 2015 determina que o processo seja conduzido de maneira equilibrada e colaborativa pelos litigantes e pelo magistrado, sem qualquer espécie de protagonismo. Assim, as partes possuem o direito à confiança de que o resultado da lide será conquistado em consonância com os fundamentos conhecidos e debatidos por elas.

Por outro lado, existirá violação à colaboração e ao diálogo processual, com a consequente afronta ao princípio do contraditório, se não concedida às partes a possibilidade de se manifestarem previamente sobre tudo que pode servir de ponto de apoio para a decisão da causa, inclusive quanto àquelas questões que o juiz pode apreciar de ofício ${ }^{22}$.

Assim, todas as vezes que o magistrado for proferir alguma decisão com base em fundamento não suscitado ou não debatido pelos litigantes, deve, obrigatoriamente, conceder o direito de prévia manifestação dos demais sujeitos processuais principais, sem que isso acarrete em redução de seus poderes jurisdicionais. É dever do juiz, portanto, ser sensível às peculiaridades do caso sob análise e, caso preveja a possibilidade de aproveitamento de fundamento não discutido, permitir a manifestação dos litigantes antes de prolatar a decisão judicial, sob pena de vulneração ao sistema processual cooperativo.

Cumpre ressaltar, ainda, que a garantia de não-surpresa deve ser observada em todo o curso do processo, inclusive no âmbito dos tribunais, uma vez que o princípio do contraditório não deve ser aplicado de maneira isolada.

A consequência da não observação da garantia do contraditório substancial é a nulidade da decisão surpresa, tendo em vista que ela afronta a característica fundamental do sistema processual adotado pelo

\footnotetext{
${ }^{21}$ MEDINA, José Miguel Garcia. Novo código de processo civil comentado: com remissões e notas comparativas ao CPC/1973. 4. ed. São Paulo: Revista dos Tribunais, 2016. p. 66.

${ }^{22}$ MARIONI, Luiz Guilherme; ARENHART, Sérgio Cruz; MITIDIERO, Daniel. Novo código de processo civil comentado. São Paulo: Revista dos Tribunais, 2015. p. 209.
} 
Novo Código de Processo Civil, pautado na colaboração entre as partes e no diálogo com o magistrado.

Em consonância com o novo paradigma estabelecido pela legislação processual civil, em especial à garantia da não-surpresa nas decisões judiciais, é necessário destacar que o Colendo Superior Tribunal de Justiça, no julgamento do Recurso Especial no 1.676.027/PR, com relatoria do Ministro Herman Benjamin, da Segunda Turma, decretou a nulidade de uma decisão judicial, por violação ao artigo 10 do Código de Processo Civil ${ }^{23}$.

O referido precedente demostra que o entendimento adotado pelo Superior Tribunal de Justiça está de acordo com o modelo de contraditório instituído pelo Código de Processo Civil, que veda definitivamente a prolação de decisões surpresas no curso da lide. Corrobora, também, que a garantia do contraditório deve ser aplicada em todos os âmbitos, independentemente do juízo ou grau de jurisdição em que os autos se encontram.

Convém ressaltar, ainda, que a consequência da observância do princípio do contraditório e, mais precisamente, da garantia da nãosurpresa é a melhor qualidade da prestação jurisdicional e a redução do número de recursos à instância superior, tendo em vista que as partes contribuem para a formação do convencimento do magistrado.

Dierle Nunes, dissertando sobre o tema, aponta que uma vez respeitado o contraditório substancial, diminui-se o tempo do processo, uma vez que o número de recursos diminui ou, ao menos, reduz consideravelmente a chance de seu provimento, possibilitando a execução imediata das decisões ${ }^{24}$.

Portanto, pode-se constatar que a consequência da observância do princípio do contraditório e, mais precisamente, da garantia de nãosurpresa é a melhor qualidade da prestação jurisdicional, já que as partes influenciam na formação da decisão. De outro lado, a não observação do referido princípio gera a nulidade da decisão surpresa, por afronta às normas fundamentais estabelecidas pelo Código de Processo Civil de 2015 .

${ }^{23}$ BRASIL. Superior Tribunal de Justiça. Recurso especial n. 1.676.027/PR, Relator Ministro Herman Benjamin, Segunda Turma, Julgado em 26/09/2017, Publicado em 11/10/2017. Disponível em:

$<$ https://ww2.stj.jus.br/processo/revista/documento/mediado/?componente=ATC\&sequencial $=74572$ $858 \&$ num_registro $=201701314840 \&$ data $=20171219 \&$ tipo $=51 \&$ formato $=P D F>$. Acesso em: 20 jun. 2018.

${ }^{24}$ NUNES. Dierle José Coelho. Et al. Curso de direito processual civil: fundamentação e aplicação. Belo Horizonte: Fórum, 2011. p. 84. 


\section{CONSIDERAÇÕES FINAIS}

Contraditório pode ser entendido como o direito que os sujeitos processuais possuem de expor os seus argumentos e apresentar as provas que julgarem pertinentes para a resolução da lide, antes que qualquer decisão seja tomada. É o direito de manifestação, ou seja, diante dos argumentos apresentados por uma parte, a outra precisa ser comunicada e ter a oportunidade de rebatê-los.

Essa garantia processual possui duas dimensões principais, a formal e a substancial. Permitir a mera participação do litigante no processo é a dimensão formal do princípio. Já a concepção substancial do contraditório, diz respeito ao poder de influência do litigante no processo em que está submetido. Para sua contemplação, é necessário que se autorize que a parte seja ouvida, mas em condições de influenciar a decisão a ser proferida pelo magistrado.

O princípio do contraditório ganhou nova perspectiva no cenário nacional com a elaboração do Código de Processo Civil de 2015, a chamada dimensão substancial, sendo que uma de suas principais funções é garantir que não haja decisão surpresa no curso do processo.

Assim, a nova sistemática adotada legislação processual civil impossibilita a prolação de decisão surpresa, uma vez que o magistrado fica obrigado a submeter todas as matérias invocadas pelas partes ao crivo do contraditório antes de decidir.

De acordo com o artigo 10 do Código de Processo Civil, o magistrado não pode decidir, seja qual for o grau de jurisdição, com base em fundamento que não tenha dado aos litigantes a oportunidade de se manifestar, ainda que se trate de matéria de ordem pública, ou seja, que deva ser decidida de ofício.

Dessa forma, a consequência da não observação do princípio do contraditório substancial, instituído pela referida norma, é a nulidade da decisão surpresa, tendo em vista que ela viola a sistemática processual adotada pelo diploma processual civil, pautado na cooperação entre as partes e o no diálogo magistrado.

A jurisprudência do Colendo Superior Tribunal de Justiça, conforme asseverado, em consonância com a legislação em vigência, tem reconhecido a nulidade das decisões surpresas, por afronta ao artigo 10 do Código de Processo civil, conforme se observada do julgamento do Recurso Especial n. ${ }^{\circ}$ 1.676.027/PR. 
O presente artigo não pretende dar resposta a todas as indagações relacionadas ao instituto em análise, uma vez que se trata de assunto complexo e atual, porém, é necessário concluir que de acordo com o modelo de contraditório instituído pelo novo diploma processual civil, as decisões surpresas devem ser declaradas nulas.

Não se ignora que a real observância deste princípio pode trazer relutância e gerar certo incômodo aos operadores do direito habituados à sistemática anterior. Todavia, é dever dos juristas assegurar a efetividade desta garantia, como medida de aprimoramento da jurisdição, de democratização do processo e de legitimação das decisões judiciais.

\section{REFERÊNCIAS BIBLIOGRÁFICAS}

BRASIL. Constituição (1988). Constituição da República Federativa do Brasil. Disponível em: <http://www.planalto.gov.br/ccivil_03/constituicao/constituicaocompilado.htm>. Acesso em: 10 ago. 2018.

BRASIL. Lei 13.105/2015 (Novo Código de Processo Civil). Disponível em: <http://www.planalto.gov.br/CCIVil_03/_Ato2015-2018/2015/Lei/L13105.htm>. Acesso em: 10 ago. 2018.

BRASIL. Superior Tribunal de Justiça. Recurso especial n. 1.676.027/PR, Relator Ministro Herman Benjamin, Segunda Turma, Julgado em 26/09/2017, Publicado em 11/10/2017. Disponível em: $<$ https://ww2.stj.jus.br/processo/revista/documento/mediado/?componente $=$ ATC $\&$ sequencial $=74572$ $858 \&$ num_registro $=201701314840 \&$ data $=20171219 \&$ tipo $=51 \&$ formato $=P D F>$. Acesso em: 20 jun. 2018

CABRAL, Antônio do Passo. O contraditório como dever e a boa-fé processual objetiva. Revista de Processo. São Paulo, SP. v. 126. ago./2005.

CINTRA, Antônio Carlos de Araújo; GRINOVER, Ada Pellegrini; DINAMARCO, Cândido Rangel. Teoria geral do processo. 24. ed. São Paulo: Malheiros, 2008.

FREITAS, José Lebre de. Introdução ao processo civil: conceito e princípios gerais à luz do código revisto. Coimbra: Coimbra Editora, 1996.

LAMY, Eduardo de Avelar. Considerações sobre a influência dos valores e direitos fundamentais no âmbito da teoria processual. Disponível em:

<https://periodicos.ufsc.br/index.php/sequencia/article/view/2177-7055.2014v35n69p301〉. Acesso em: 18 mar. 2018.

MARINONI, Luiz Guilherme. Novas linhas do processo civil. 4. ed. São Paulo: Malheiros, 2000.

MARIONI, Luiz Guilherme; ARENHART, Sérgio Cruz; MITIDIERO, Daniel. Novo código de processo civil comentado. São Paulo: Revista dos Tribunais, 2015. 
MEDINA, José Miguel Garcia. Novo código de processo civil comentado: com remissões e notas comparativas ao CPC/1973. 4. ed. São Paulo: Revista dos Tribunais, 2016.

MESQUITA, Gil Ferreira de. Princípios do contraditório e da ampla defesa no processo civil brasileiro. São Paulo: Editora Juarez de Oliveira, 2003.

NERY JUNIOR, Nelson. Princípios do processo civil na constituição federal. 8. ed. São Paulo: Revista dos Tribunais, 2004.

NUNES. Dierle José Coelho. Et al. Curso de direito processual civil: fundamentação e aplicação. Belo Horizonte: Fórum, 2011.

OLIVEIRA NETO, Olavo de; MEDEIROS NETO, Elias Marques de; OLIVEIRA, Patrícia Elias Cozzolino de. Curso de direito processual civil. São Paulo: Verbatim, 2015.

RUBIN, Fernando. O contraditório na visão cooperativa do processo. Revista Dialética de Direito Processual - RDDP. São Paulo, SP. n. 94. jan./2011.

TARTUCE, Fernanda. Igualdade e vulnerabilidade no processo civil. Rio de Janeiro: Forense, 2012.

THEODORO JÚNIOR, Humberto. A Constitucionalização do processo no estado democrático brasileiro. In: CÂMARA, Alexandre Freitas; GAIO JÚNIOR, Antônio Pereira (Coord.). Novo CPC: reflexões e perspectivas. Belo Horizonte: Del Rey, 2014. 